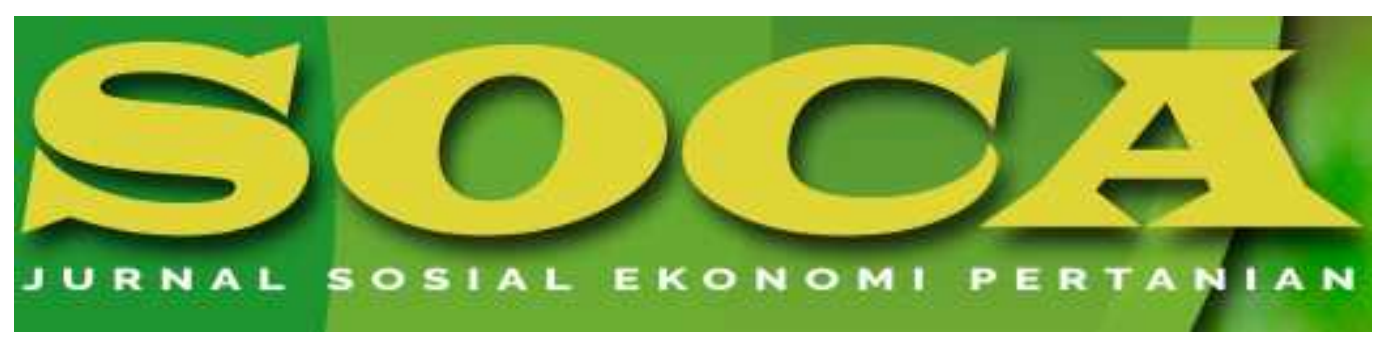

https://ojs.unud.ac.id/index.php/soca

\title{
PENINGKATAN NILAI EKONOMI PADA RTM (Rumah Tangga Miskin) MELALUI PROGRAM BEKERJA KEMENTERIAN PERTANIAN
}

\author{
Supardi Rusdiana dan Tike Sartika \\ Balai Penelitan Ternak Ciawi-Bogor, Po.Box 221 Bogor Jawa Barat, Indonesia \\ E-mail: s.rusdiana20@gmail.com \\ HP: 081282010532
}

\begin{tabular}{l} 
Kata Kunci: \\
peningkatan \\
nilai ekonomi \\
RTM melalui \\
program \\
bekerja \\
\hline
\end{tabular}

\begin{abstract}
Abstrak
Hampir semua masyarakat di Kecamatan Salopa usaha memelihara ayam kampung, karena ayam kampung merupakan komponen yang sangat penting bagi kehidupan masyarakat. Tujuan tulisan ini adalah untuk mengetahui peningkatan nilai ekonomi pada RTM (Rumah Tangga Miskin) melalui program bekerja Kementerian Pertanian Badan Litbang Pertanian, Balai Penelitian Ternak. Penelitian menggunakan survey terhadap 54 RTM/peternak Desa Mandalahayu 27 RTM//petermak dan Desa Mandalawangi 27 RTM/peternak. Data primer dan data sekunder di analisis secara deskriptif, kuantitatif dan ekonomi. Hasil penelitian menujukkan, pendapatan RTM / peternak di Desa Mandalahayu sebasar Rp.2.480.000,-/periode dengan B/C ratio sebesar 1,08 dan di Desa Mandalawangi sebasar Rp.2.510.000,/periode dengan B/C ratio sebesar 1,10. Dapat dikatakan usaha pembesaran DOC ayam kampung di RTM secara ekonomi belum layak. Namun bila untuk usaha sampingan, tabungan dan pengisi waktu, dapat dikatakan layak, karena ayam dapat dijual sebagai sumber kebutuhan mendadak bagi peternak. Kondisi RTM di beberapa tempat sudah lebih baik, sejak tercatat sebagai RTM penerima ayam. Program bekerja Kementerian Pertanian, diharapkan dapat pengentasan kemiskinan, dilakukan akserasi pembangunan pertanian, sehingga pendapatan peternak meningkat dan angka kemiskinan terus ditekan atau berkurang
\end{abstract}




\section{IMPROVING ECONOMIC VALUE ON RTM (Poor Households) THROUGH PROGRAMS TO WORK THE MINISTRY OF AGRICULTURE}

\section{Keywords: \\ increasing \\ economic value of RTM, through work programs}

\begin{abstract}
Abstrak
Almost all communities in Salopa Sub district are trying to raise livestock from native chickens, because free-range chicken is a very important component for people's lives. The purpose of the paper is to find out the increase in economic value of (poor households) RTM through the work program of the Ministry of Agriculture, IAARD, Animal Research Institute. The study used a survey of 54 RTM/farmer fard Mandalahayu Village 27 RTM/farmer and Mandalawangi Village 27 RTM/farmer. Primary data and secondary data are analyzed descriptively, quantitatively and economically. The results showed that the income of RTM/farmer in Mandalahayu Village was IDR.2.480.000/period with $B / C$ ratio of 1.08 and in the village of Mandalawangi as much IDR.2.510.000/period with $B / C$ ratio of 1.10 . It can be said that the effort to enlarge DOC of chicken in RTM is not economically feasible. But if for a side business, savings and time fillers, it can be said to be feasible, because chickens can be sold as a source of sudden needs for farmers. The program works by the Ministry of Agriculture, expected to alleviate poverty, carry out agricultural development harmonization, so that farmers' income increases and poverty rates continue to be reduced or reduced
\end{abstract}

How to Cite (APA 6 ${ }^{\text {th }}$ Style):

Rusdiana, S., \& Sartika, T. (2020). Peningkatan Nilai Ekonomi Pada RTM (Rumah Tangga Miskin) Melalui Program Bekerja Kementerian Pertanian. SOCA: Jurnal Sosial Ekonomi Pertanian, 14(1), 146-157.

https://doi.org/https://doi.org/10.24843/SOCA.2020.v14.i01.p12

\section{PENDAHULUAN}

Ternak ayam kampung (KUB-SenSi-1) adalah salah satu jenis ternak yang potensial dan dapat dikembangkan di seluruh wilayah di Indonesia. Ayam tersebut dapat dikembangkan untuk produksi daging dan telur, namun secara umum ayam kampung di Indonesia masih difokuskan untuk usaha sampingan atau usaha pengisi waktu. Wibowo dan Sartika (2010) menyatakan peternak pada umumnya melakukan usaha ayam kampung masih menggunakan bibit, yang bearsal dari hasil keturunannya itu sendiri. Hal ini disebabkan belum tersebarnya secara meluas dalam jumlah, maupun wilayah bibit ayam yang berkualitas baik, atau disebut Ayam Kampung Unggul Balitnak (KUB), yang merupakan hasil penelitian Balai Penelitian Ternak. Ayam kampung memiliki potensi untuk di pengembangan, karena cara pemeliharaan yang relatif mudah dilakukan kuga mudah cara menjualnya. Dalam rangka mengatasi kemiskinan, tahun 2018, melalui program Kementerian Pertanian Bekerja untuk memberikan ayam kampung kepada RTM (Rumah Tangga 
Miskin) beruupa DOC, pelengkapan kandang, pakan dalan lainnya, di setiap wilayah di Indonesia.

Salah satunya adalah di Kecamatan Salopa Kabupaten Tasikmalaya yang sebagian RTM-nya telah menerima ayam kampung berupa DOC. Hampir semua masyarakat di Kecamatan Salopa usaha memelihara ayam kampung, karena ayam kampung merupakan komponen yang sangat penting bagi kehidupan masyarakat. Ayam kampung dapat dipelihara dengan baik, dengan melalui pemanfaatan sumberdaya alam yang tersedia di sekitarnya. Selain itu juga sebagai salah satu fungsi ayam kampung untuk membantu perekonomian peternak. Ayam kampung dipelihara oleh peternak sebagai tabungan keluarga, tambahan penghasilan, dan memenuhi kebutuhan finansial yang sifatnya mendadak. Misi Kementerian Pertaian yaitu menemukan dan membangun inovasi pertanian (teknologi, kelembagaan dan kebijakan) yang maju dan strategis melalui penyediaan materi maupun teknologi dasar yang dapat diadopsikan kepada para pengguna di spesifik lokasi.

Sampai saat ini Badan Litbang telah menghasilkan banyak teknologi, namun terjadi gap antara teknologi yang tersedia dibanding dengan teknologi yang diaplikasikan di masyarakat (Puslitbangnak. 2011). Oleh karena itu dibutuhkan akselerasi pemanfaatan teknologi melalui komunikasi antara lembaga penelitian dengan dinas terkait yang pada akhirnya teknologi dapat mengalir dengan baik ke para peternak dan akan diperoleh feedback dari pengguna (Puslitbangnak, 2011). Kegiatan bekerja-bekerja sebagai upaya untuk mensejahterakan RTM/peternak. Program bedah kemiskinan memberikan 10 juta ekor ayam secara gratis pada masyarakat miskin RTM di seluruh wilayah Indonesia. Asumsi kelayakan finansial usaha ayam kampung KUB dan SenSi-1 yang diberikan kepada RTM berupa DOC untuk pendapatannya sebesar Rp 2,2 juta per bulan, yang disebut miskin pendapatan Rp 1.400.000,- (Kementerian Pertanian 2018). Artinya, dengan pendapatan Rp.1.000.000,- ditambah Rp.2.200.000,- pemasukan tambahan, RTM dapat menghasilkan Rp3.200.000,-/bulan. Lepas dari kemiskinan 6 (enam) bulan kemudian.

RTM diperkirakan sudah mampu memperoleh pendapatan sekitar Rp.2.300.000,-/RTM/bulan atau Rp.550.000,-/RTM/bulan. Besaran ini jauh dari batas garis kemiskinan yang sekitar Rp 370.000,-/RTM/bulan. Di tengah upaya menurunkan jumlah masyarakat miskin di setiap wilayah di Indonesia, program bekerja terseut akan mempunyai posisi penting bagi RTM (Sulaiman 2018). Mengingat program bekerja mempunyai target dalam waktu kurang dari setahun sudah mampu membalikkan status rumah tangga petani miskin di perdesaan menjadi rumah tangga sejahtera. Kontribusi ternamk ayam selain sebagai penyumbang telur juga daging secara nasional. Namun kontribusi daging asal ayam kampung kedepan dapat lebih dipacu peningkatnnya, mengingat bahwa, daging dan telur ayam secara nutrisi dan kesehatan memiliki kelebihan dibandingkan dengan ternak lain. Wibowo dan Sartika (2010) menyatakan bahwa, ayam kampung lokal telah berkembang secra luas di seluruh wilayah Indonesia, dan kemampuan beradaptasi dengan lingkungan dapat diakui oleh masyarakat sebagai kehidupan yang tidak dapat dipisahkan.

Hasil penelitian Sartika dan Iskandar (2007) telah berhasil mengidentifikasi 41 rumpun ayal lokal yang hidup di Indonesia baik yang asli maupun pendatang yang sudah menempuh siklus minimal 3 generasi. Lebih lanjut dikemukakan bahwa 
ayam lokal mempunyai multi fungsi sebagai hobby, suara, hias, daging dan telur. Untuk itu tersedia beberapa alternatif skema yang dapat dikembangkan sesuai dengan kondisi spesifik wilayah RTM di pedesaan. Ketersediaan bahan baku pakan yang terjamin dengan harga kompetitif merupakan salah satu pilar usaha produksi ayam. Biaya pakan merupakan salah satu komponen terbesar dalam struktur biaya produksi ternak yang dikelola secara intensif maupun semi intensif. Efisiensi penggunaan pakan akan berpengaruh langsung kepada efisiensi usaha secara keseluruhan. Potensi wilayah akan membuka peluang usaha bagi perwujudan program Bekerja bagi RTM melalui dukungan terhadap usaha produksi ayam di sekitar wilayah pedesaan.

Ayam kampung merupakan salah satu rumpun ternak hasil rekayasa teknologi breeding Balai Penelitian Ternak. Penelitian dan inovasi ayam kampung ini merupakan hasil penelitian yang dilakukan dalam kurun waktu yang cukup panjang lebih dari $\geq 10$ tahun. Kegiatan perbanyakan dan penyebaran bibit ayam kampung dapat dilakukan dengan berbagai metode yaitu introduksi melalui pola program Bekerja Kemnetrian Pertanian. Kondisi tersebut diatas mengindikasikan bahwa pengembangan komoditas ayam kampung KUB dan SenSi sangat potensial dillakukan. Menurut Sulaiman (2018) sangat optimis dan pasti program bekerja, dapat pengentasan kemiskinan, karena dilakukan dengan akserasi pembangunan pertanian di pedesaan, sehingga pendapatan peternak akan semakin meningkat dan angka kemiskinan terus ditekan atau berkurang. Tujuan tulisan ini guna mengetahui peran program bekerja terhadap RTM (Rumah Tangga Miskin), melalui pemberian ayam kampung DOC dalam mendukung perbanyakan ayam, untuk menigkatkan pendapatan dan kesejahteraan peternak.

\section{METODE PENELITIAN}

\section{Waktu dan Tempat Penelitian}

Penelitian dilakukan di Desa Mandalahayu dan Desa Mandalawangi Kecamatan Salopa Kabupeten Tasikmalaya, Jawa Barat tahun 2018. Lokasi penelitian merupakan kantong usaha ayam KUB dan SenSi dan secara umum pemeliharaanya hasil pemberian dari program beerja Kementerian pertanian RTM (Rumah Tangga Miskin). Lokasi penelitin didukung dengan lahan pertanian, lahan sawah, ladang, lahan perhutani milik BUMN, transortasi dan pasar, sehingga usaha ayam sangat cocok untuk dikembangkan. Penelitian menggunakan survey terhadap $54 \mathrm{RTM} /$ peternak yaitu Desa Mandalahayu $27 \mathrm{RTM} / /$ peternak dan Desa Mandalawangi $27 \mathrm{RTM} /$ peternak. Data primer diperoleh langsung dari hasil wawancara dan pengsisian kuisioner yang telah disipakan. Sedangkan data sekunder diperoleh dari Dinas Pertanian dan Petenakan Kabupaten Tasikmalaya. Data primer dan data sekunder dianalisis secara deskriptif, kuantitatif dan analisis ekonomi.

\section{Analisis Data}

Materi atau data yang dikumpulkan adalah semua data penggunaan input produksi yang meliputi, jumlah ayam yang dipelihara hasil pembagian dari lembaga Kementerian Pertanian, konsentrat dan tenaga kerja peternak. Sedangkan data produksi yang dihitung adalah jumlah produksi ayam yang masih hidup dan bobot badan serta harga jual betina dan jantan beragai umur. Asumsi nilai dan nilai jual 
ayam hasil usaha RTM (rumahTangga Miskin) diasumsikan kedalam biaya penyusutan, karena masing-masing RTM/peternak tidak mengeluarkan biaya untuk pemebelian bibit, pakan selama pemeliharaan. Data yang diperoleh semuanya diambil dari kronologis atau kerjadian dari awal memelihara sampai ayam siap dijual. Analisis data terdiri atas gabungan pendekatan diskriptif dan analisis menggunakan $\mathrm{R} / \mathrm{C}$ atau Return Cost Ratio untuk efisiensi penggunaan modal dan produktifitas laba-rugi (Loing dan Makalew 2016).

Besaran biaya tenaga kerja peternak, berdasarkan jumlah dan waktu kerja yang digunaan untuk mengurus ayam kampung milik sendiri biasanya tdak dihitung (Dewanti dan Sihombing 2012). Data empiris adalah data yang diperoleh kemudian diuji terlebih dahulu, sehingga dapat diketahui nilai ekoomi pada beberapa model usaha baik industri maupun usaha peterak (Istikomah et al., 2016). Kriteria nilai ekonomi pada usaha ayam kampung dapat dihtung berdasaran dengan $\mathrm{B} / \mathrm{C}<1$, maka usaha tidak ekonomis, $\mathrm{B} / \mathrm{C}>1$ usaha lancar bila $\mathrm{B} / \mathrm{C}=1$ usaha tidak rugi tidak untung seimbang (Rosganda dan Rusdiana 2012) Peternak dapat mempertimbangkan kembali apakah usahanya akan dilanjutkan atau tidak.

\section{HASIL DAN PEMBAHASAN}

Topografi di Kecamatan Salopa bergelombang/berbukit dengan elevasi antara 1300 -1500 m dpl, didukung oleh curah hujan yang tinggi dan berhawa sejuk, dengan suhu udara mencapai $8-25^{\circ} \mathrm{C}$. Kecamatan Salopa mempunyai 9 Desa, dimana setiap Desa terpilih sebagai RTM penerima bantuan ayam kampung DOC KUB dan Sen-1.dan setelahnya 6 bulan biaya pemeliharaan diserhkan kepada masing-masing RTM sebagai yang mngelolanya ayam berikutnya. Program Bekerja dapat menjadi solusi permanen pengentasan kemiskinan dengan menyasar jangka pendek, jangka menengah, dan jangka panjang. Jangka pendek, tanaman sayuran bisa menjadi solusi karena dalam jangka 3 (tiga) bulan sudah bisa panen. Jangka menengah RTM telah diberikan ayam DOC, untuk dipelihara, karena ayam sudah bisa berproduksi/bertelur dalam waktu 6 bulan. Program bekerja bisa mewujudkan klaster ekonomi bagi RTM yang fokus, sehingga bisa menopang skala industri di Kecamatan Salopa.

Proyeksi program bekerja di Kecamatan Salopa Kabupaten Tasikmalaya yang berbasis ayam kampung akan berdampak pada peningkatan ketersediaan pangan asal hewani. Program bekerja juga pada saat yang sama akan berdampak terhadap membaiknya kondisi sosial, budaya dan ekonomi RTM-nya yang semakin meningkat khusunya di Kecamatan Salopa. Prediksi 1-2 tahun pengangguran di Kecamatan Salopa diharapkan dapat menurun, sehingga keresahan masyarakat RTM sedikit berkurang. Program bekerja tersebut turut menyediakan lapangan kerja dan sumber pendapatan bagi masyarakat sekitar Kecamatan salopa. Secara tidak langsung, program bekerja dapat mengurangi laju jumlah masyarakat yang mencari pekerjaan ke kota (urbanisasi) dan juga diharrapkam RTM/peternak dapat meningkatkan pendapatan dan sejahtera

Mengingat bahwa program Bekerja bertarget dalam waktu kurang dari setahun sudah mampu membalikkan status rumah tangga petani miskin (RTM) di perdesaan menjadi rumah tangga sejahtera. Proyeksi pengembangan program Bekerja berbasis Pertanian dan peternakan akan berdampak pada peningkatan ketersediaan pangan. Peningkatan konsumsi pangan dan kualitas gizi 
keluarga.Peningkatan ekonomi / pendapatan peternak sehingga akan terangkat menjadi masyarakat sejahtera. Program Bekerja pada saat akan berdampak terhadap membaiknya kondisi sosial masyarakat peternak/RTM. Harapkan pengangguran menurun sehingga keresahan masyarakat RTM juga berkurang karena program bekerja, turut menyediakan lapangan kerja dan sumber pendapatan. Karena itu, secara tidak langsung, program Bekerja dapat mengurangi laju jumlah masyarakat RTM yang mencari pekerjaan ke kota (urbanisasi). Peningkatan daya saing ekonomi nasional dan menjaga kelestarian sumber daya pertanian, perikanan dan kehutanan.

Diperlukan dukungan sumber daya manusia berkualitas melalui penyuluhan pertanian dengan pendekatan kelompok yang dapat mendukung sistem agribisnis berbasis pertanian. Perlu dilakukan pembinaan dalam rangka penumbuhan dan pengembangan kelompoktani menjadi kelompok yang kuat dan mandiri untuk meningkatkan pendapatan petani dan keluarganya (Adawiyah, 2017). Diperlukannya kerja sama antar petani dan pihak lainnya yang terkait untuk mengembangkan usahataninya. Menurut Zakaria (2010) bahwa, perlunya pembinaan kelompoktani diarahkan pada penerapan sistem agribisnis, peningkatan peranan, peran serta petani dan anggota masyarakat pedesaan lainnya. Pembinaan kelompoktani diharapkan dapat membantu menggali potensi, memecahkan masalah usahatani anggotanya secara lebih efektif, dan memudahkan dalam mengakses informasi, pasar, teknologi, permodalan dan sumber daya lainnya (Apriyantono, 2007).

Usahatani yang berkelanjutan adalah usahatani yang dapat memenuhi kebutuhan masyarakat sekarang dan masa yang akan datang akan pangan dan serat; memenuhi pelayanan ekosistem dan kehidupan yang sehat. Program pemberdayaan yang telah dilakukan memberikan manfaat bagi petani, setidaknya mengubah perilaku dan cara para tani dalam bertani. Diseminasi inovasi teknologi pada pengelolaan budidaya ternak oleh lembaga penelitian seperti Balitnak, tentunya akan sangat membantu para penyuluh pertanian di dinas-dinas pemerintah daerah, karena Balitnak sebagai penemu teknologi itu sendiri akan lebih menguasai. Konsep-konsep pengembangan modernpun banyak disarankan, oleh karena itu pendekatan RTM diharapkan dapat dijadikan sebagai langkah awal menuju masyarakat sejahtera. Kerkelanjutan dari pasa usaha pemeliharaan ayam pada setiap RTM di pesesaan, dianalogkan dengan dinamika perkembangan kelompok peternak RTM umumnya meningkat.

Memerlukan pembinaan yang dimulai dengan pembukaan wawassan melalui Bimtek, agar perkembangan ayam. Bagaimana sumberdaya alam pendukung usahatani ternak itu sendiri yang mungkin semakin berkurang, diberikan dukungan untuk berkemampuan berbisnis dalam hubungannya dengan korporasi dalam kelompok petenak. (Schader et al., 2013) dan (Anantanyu 2008). Balai Penelitian Ternak mencoba mengembangkan konsep tersebut, mengingat sifat alami peternakan yang dapat berintegrasi dengan tanaman pangan seperti tanaman jagung sehingga dapat membentuk suatu bioindustri pakan yang efisien dan ramah lingkungan. Selain itu juga pemanfaat iptek dalam kehidupan masyarakat peternak di RTM sehari-hari dapat memberikan nilai tambah dan manfaat yang besar bagi kesejahteraan RTM. Sektor pertanian dan peternakan yang menjadi sumber 
penghidupan dan juga bagi masyarakat peternak RTM, yana sudah tersentuh teknologiny oleh peternak.

Teknologi tersebut telah terbukti memberi dampak yang siginifikan pada peningkatan produktivitas dari kedua sektor pertanian dan peternakan. Koordinasi bersama TKSD dilakukan untuk menyusun exit strategiprogram Bekerja di RTM di Kabupaten Tasikmalaya. Teknologi peternakan diharapkan dapat diaplikasi sehingga dapat mempercepat teradopsinya inovasi teknologi yang lebih efisien oleh para RTM dalam rangka menunjang pendapatan peternk.

\section{Sosial dan budaya pemeliharaan ayam kampung di RTM/peternak}

Secara sosial dan budaya ayam kampung sudah dikenal dan banyak diusahakan oleh masyarakat di pedesaan. Diantaranya adalah Rumah Tangga Miskin/peternak (RTM) di Desa Mandalawangi dan di Desa Mandalahayu Kecamatan Salopa Kabupaten Tasikmalaya, yang dapat menerima ayam berupa DOC uttuk dipelihara. Secara tidak langsung RTM sudah terbiasa dan berpengalaman memelihara ayam. Jumlah awal pemeliharan rata-rata peternak sebanyak 50 ekor DOC/RTM/peternak untuk dipelihara hingga berproduksi telur dan daging. Kemampuan peternak untuk melanjutkan pemeliharaanya selama pakan tidak disubsidi oleh Pemerintah, maka dapat dilihat dari kemampuan peternak untuk biaya produksi. Perkiraan pemeliharaan selanjutnya sebesar $60 \%$ ayam di jual untuk dikembalikan biaya pakan dan sebesar $40 \%$ ayam dipelihara sampai berproduksi sehingga peternak pendapatan keuntungan. Usaha ayam dengan cara pembesaran DOC hingga $>6$ bulan berproduksi. Rataan kepemilikan ayam saat ini di peternak terlihat pada Tabel.1.

Tabel.1. Rataan kepemilikan ayam di RTM/peternak

\begin{tabular}{lcccc}
\hline \multirow{2}{*}{ Uraian } & \multicolumn{2}{c}{ Desa Mandalahayu } & \multicolumn{2}{c}{ Desa Mandalawangi } \\
\cline { 2 - 5 } & Jumlah \pm Sd & Rataan $(\%)$ & Jumlah \pm Sd & Rataan(\%) \\
\hline Ayam kampung betina & $24 \pm 0,51$ & $0,89(52.17)$ & $25 \pm 0,58$ & $0,92(53,19)$ \\
Ayam kampung jantan & $22 \pm 0,47$ & $0,81(47,82)$ & $22 \pm 0,44$ & $0,81(46,81)$ \\
Ayam yang mati & $3 \pm 0,21$ & $0,11(6,52)$ & $4 \pm 0,3,12$ & $0,11(8.51)$ \\
Ayam dikasihkan/diberikan & $2 \pm 0,11$ & $0,07(4,35)$ & $2 \pm 0,11$ & $0,07(4,26)$ \\
\hline
\end{tabular}

Tabel 1, menunjukkan bahwa, status betina dan jantan mulai dewasa masih banyak dipelihara oleh RTM. Nilai jual ayam betina calon induk umur $>5$ bulan dengan rata-rata harga antara sebesar Rp.20.000-30.000,-/ekor, dan jantan umur $>5$ bulan rata-rata harga sebesar Rp.50.000-100.000,-/ekor. Harga jual ayam calon induk dan jantan siap potong atau siap untuk pejantan dilihat dari bobot badan dan penampilan ayam. Pemasaran ayam tidak sulit, karena hampir semua masyarakat menyukai daging ayam kampung. Dukungan kelembagaan Pemerintah Pusat dan daerah dengan program bekerja pembagian ayam pada RTM cukup rasional dan mengarah pada usaha komersial. Artinya untuk saling mendukung untuk berjalannya usaha ayam di RTM, perlunya pemodal, terutama untuk biaya pakan dan kandang, pemsaran ayam cukup baik.

\section{Nilai ekonomi usaha ayam di RTM/Peternak}

Usaha pembesaran ayam dari DOC ditingkat RTM/peternak dengan skala pemeliharaan rata-rata 46-47 ekor. Periode usaha dimulai pada ayam umur DOC 
sampai umur 24 minggu sudah berproduksi telur dan daging. Nilai keuntunagnakan RTM dapat dihitung berdasarkan waktu pemeliharaan, jumlah biaya yang dikleuarkan dan jumlah ayam yang produksi dan terjual. Usaha diawali dengan pembuatan kandang, peralatan kandang, tempat minum, pakan, sebagai biaya tetap dan sarana produksi berupa bibit, pakan, obat-obatan. Tenaga kerja peternak tidak dihitung ke dalam biaya produksi, namun diasumian kedalam biaya pakan dan harga pakan ayam di asumsikan sebesar Rp.4.000,-/kg. Setiap ayam akan membutuhkan pakan yang berbeda, sehingga perlu ditata dalam pemberian pakannya sesuai standar pemebrian pakan (Iskandar et al., 2018). Standar pemberian pakan ayam KUB dan SenSi-1 untuk RTM/peternak Desa Mandalahayu dan Desa Mandalawangi hasil rekayasa dan Inovasi Balitnak terlihat pada Tabel.2 dan 3.

Tabel 2. Standar pemberian pakan ayam kampung dan harga pakan di Desa Mandalahayu

\begin{tabular}{|c|c|}
\hline Umur minggu & Gram/ekor/hari, jumlah ayam, harga pakan dan jumlah biaya \\
\hline 1 & $5 \mathrm{gr} / 1000$ atau 0.005 gr $\times 46$ ekor $\times 7$ hari $\times$ Rp. $4.000=$ Rp. 6.400 \\
\hline 2 & $10 \mathrm{gr} / 1000$ atau $0,01 \mathrm{gr} \times 46$ ekor $\times 7$ hari $\times$ Rp. $4.000=$ Rp. 12.880 \\
\hline 3 & 15 gr/ 1000 atau 0,015 gr $\times 46$ ekor $\times 7$ hari $x$ Rp. $4.000=$ Rp. 19.320 \\
\hline 4 & $20 \mathrm{gr} / 1000$ atau 0,02 gr $\times 46$ ekor $\times 7$ hari $\times$ Rp. $4.000=$ Rp. 25.760 \\
\hline 5 & $32 \mathrm{gr} / 1000$ atau 0,032 gr $\times 46$ ekor $\times 7$ hari $\times$ Rp. $4.000=$ Rp.41.216 \\
\hline 6 & $37 \mathrm{gr} / 1000$ atau $0,037 \mathrm{gr} \times 46$ ekor $\times 7$ hari $\times$ Rp. $4.000=$ Rp. 47.656 \\
\hline 7 & $42 \mathrm{gr} / 1000$ atau 0,042 gr $x 46$ ekor $\times 7$ hari $x$ Rp. $4.000=$ Rp. 54.096 \\
\hline 8 & $55 \mathrm{gr} / 1000$ atau 0,055 gr $\times 46$ ekor $\times 7$ hari $x$ Rp. $4.000=$ Rp. 70.840 \\
\hline 9 & $60 \mathrm{gr} / 1000$ atau 0,06 gr $\times 46$ ekor $\times 7$ hari $\times$ Rp. $4.000=$ Rp.77.280 \\
\hline 10 & $60 \mathrm{gr} / 1000$ atau 0.06 gr $\times 16$ ekor $\times 7$ hari $x$ Rp. $4.000=$ Rp.77.280 \\
\hline 12 & $70 \mathrm{gr} / 1000$ atau 0,07 gr $\times 46$ ekor $\times 7$ hari $\times$ Rp. $4.000=$ Rp.90.160 \\
\hline 14 & 75 gr/ 1000 atau 0,075 gr x 46 ekor x 7 hari x Rp. $4.000=$ Rp.96.600 \\
\hline 16 & $80 \mathrm{gr} / 1000$ atau 0,08 gr $\times 46$ ekor $\times 7$ hari $\times$ Rp. $4.000=$ R. 103.040 \\
\hline 18 & $90 \mathrm{gr} / 1000$ atau 0,09 gr $\times 46$ ekor $\times 7$ hari $\times$ Rp.4.000 = Rp.115.920 \\
\hline 20 & $100 \mathrm{gr} / 1000$ atau 0,1 gr $\times 46$ ekor $\times 7$ hari $x$ Rp. $4.000=$ Rp. 128.800 \\
\hline 22 & $100 \mathrm{gr} / 1000$ atau 0,1 gr $\times 46$ ekor $\times 7$ hari $\times$ Rp. $4.000=$ Rp. 128.800 \\
\hline 24 & $\begin{array}{l}100 \mathrm{gr} / 1000 \text { atau } 0,1 \text { gr } \times 46 \text { ekor } \times 7 \text { hari } \times \text { Rp. } 4.000=\text { Rp. } 128.800 \\
\text { jumlah biaya pakan ayam DOC sampai umur } 24 \text { minggu } \\
\text { Rp.1.224.848 }\end{array}$ \\
\hline
\end{tabular}

Sumber : Iskandar et al., (2018) data di olah (2019)

Tabel 3. Standar pemberian pakan ayam kampung dan harga pakan Desa Mandalawangi

\begin{tabular}{|c|c|}
\hline Umur minggu & Gram/ekor/hari, jumlah ayam, harga pakan dan jumlah biaya \\
\hline 1 & 5 gr $/ 1000$ atau 0.005 gr $x 47$ ekor $\times 7$ hari $x$ Rp. $4.000=$ Rp. 6.580 \\
\hline 2 & 10 gr $/ 1000$ atau 0,01 gr $x 47$ ekor $\times 7$ hari $x$ Rp. $4.000=$ Rp. 13.160 \\
\hline 3 & 15 gr $/ 1000$ atau 0,015 gr $\times 47$ ekor $\times 7$ hari $\times$ Rp. $4.000=\operatorname{Rp} .19 .740$ \\
\hline 4 & $20 \mathrm{gr} / 1000$ atau 0,02 gr $\times 47$ ekor $\times 7$ hari $\times$ Rp. $4.000=$ Rp. 26.320 \\
\hline 5 & $32 \mathrm{gr} / 1000$ atau 0,032 gr $\times 47$ ekor $\times 7$ hari $\times$ Rp. $4.000=$ Rp.42.112 \\
\hline 6 & $37 \mathrm{gr} / 1000$ atau 0,037 gr $\times 47$ ekor $\times 7$ hari $x$ Rp. $4.000=$ Rp.48.692 \\
\hline 7 & 42 gr/ 1000 atau 0,042 gr $\times 47$ ekor $\times 7$ harix Rp. $4.000=$ Rp.55.272 \\
\hline 8 & $55 \mathrm{gr} / 1000$ atau 0,055 gr $\times 47$ ekor $\times 7$ hari $\times$ Rp. $4.000=$ Rp. 72.380 \\
\hline 9 & 60 gr/ 1000 atau 0,06 gr $x 47$ ekor $x 7$ hari $x$ Rp. 4.000 \\
\hline
\end{tabular}




\begin{tabular}{|c|c|c|}
\hline 10 & 60 gr/ 1000 atau 0.06 gr $\times 47$ ekor $\times 7$ hari $x$ Rp. 4.000 & $=\mathrm{Rp} .78 .969$ \\
\hline 12 & $70 \mathrm{gr} / 1000$ atau 0,07 gr $\times 47$ ekor $\times 7$ hari $x$ Rp. 4.000 & $=\operatorname{Rp} .92 .120$ \\
\hline 14 & 75 gr $/ 1000$ atau 0,075 gr $\times 47$ ekor $\times 7$ hari $\times$ Rp. 4.000 & $=$ Rp.98.700 \\
\hline 16 & 80 gr/ 1000 atau 0,08 gr x 47 ekor $\times 7$ hari x Rp.4.000 & $=\mathrm{Rp} .105 .280$ \\
\hline 18 & $90 \mathrm{gr} / 1000$ atau 0,09 gr $\times 47$ ekor $\times 7$ hari $\times$ Rp. 4.000 & $=$ Rp. 118.440 \\
\hline 20 & $100 \mathrm{gr} / 1000$ atau 0,1 gr $x 47$ ekor $\times 7$ hari $x$ Rp. 4.000 & $=\operatorname{Rp} .131 .600$ \\
\hline 22 & 100 gr/ 1000 atau 0,1 gr $x 47$ ekor $\times 7$ hari $x$ Rp. 4.000 & $=\operatorname{Rp} .131 .600$ \\
\hline 24 & $\begin{array}{l}100 \mathrm{gr} / 1000 \text { atau } 0,1 \mathrm{gr} \times 47 \text { ekor } \times 7 \text { hari } \times \text { Rp. } 4.000 \\
\text { jumlah biaya pakan ayam DOC sampai umur } 24 \text { mingg } \\
1.252 .534\end{array}$ & \\
\hline
\end{tabular}

Sumber : Iskandar et al., (2018) data di olah (2019)

Tabel 2-3, menujukan bahwa, dari setiap umur ayam terdapat perbedaan pemberian pakan. Semakin umur ayam bertambah akan semakin bertambah pula kebutuhan pakan. Biaya produksi pakan dapat disesuaikan dengan umur ayam, jumlah ayam dan waktu pemeliharaan. Ayam yang dipelihara oleh RTM/peternak adalah milik sendiri, sehingga cara pemeliharaannya cukup sederhana.

RTM/peternak di Desa Mandalahayu untuk biaya pembelian bibit sebanyak 46 ekor/DOC dengan asumsi harga sebesar Rp.7.000,-/ekor atau sebesar Rp.329.000,-. Biaya kandang rata-rata sebesar Rp.500.000,-/unit/peternak. Asumsi biaya penyusutan kandang sebasar 10\%/tahun atau sebesar Rp.50.000,/tahun. Biaya peralatan kandang sebesar Rp.100.000,-/tahun habis pakai. Biaya obat-obatan paket sebesar Rp.40.000,-/ periode dan biaya pakan umur DOC atau 1 minggu sampai umur 24 minggu sebesar Rp.1.224.848,-/ periode. Jumlah biaya produksi pada usaha pemeliharaan ayam sebesar Rp.1.743.848,-/ periode.

Asumsi nilai jual ayam betina siap prduksi sebanyak 24 ekor x harga sebesar Rp.30.000 sebesar Rp.720.000,- dan nilai jual ayam jantan siap potong dan siap dijadikan pejantan sebanyak 22 ekor $\mathrm{x}$ harga sebasar 80.000,-/ekor sebesar Rp.1.760.000,-. Jumlah pendapatan kotor sebesar Rp.2.480.000,-/periode. Jumlah pendapatan bersih sebesar Rp.736.152,-/peternak, nilai B/C ratio sebesar 1,08

RTM/peternak di Desa Mandalawangi untuk biaya pembelian bibit sebanyak 47 ekor/DOC dengan harga sebesar Rp.7.000,-/DOC/ekor sebesar Rp.329.000,/peternak. Biaya kandang rata-rata sebesar Rp.500.000,-/unit/peternak biaya penyusutan kandang sebasar 10\%/tahun atau sebesar Rp.50.000,-/tahun. Biaya peralatan kandang sebesar Rp.100.000,-/tahun habis pakai. Biaya obat-obatan paket sebesar Rp.40.000,-/perode habis pakai. Biaya pakan umur DOC atau 1 minggu sampai umur 24 minggu sebesar Rp.1.252.534,-/periode Jumlah biaya produksi pada usaha pemeliharaan ayam sebesar Rp.1.771.534.

Asumsi nilai jual ayam betina siap produksi sebanyak 25 ekor $\mathrm{x}$ harga sebesar Rp.30.000,-/ekor sebesar Rp.750.000,- dan nilai jual ayam jantan siap potong dan siap dijadikan pejantan sebanyak 22 ekor x harga sebasar 80.000,-/ekor sebesar Rp.1.760.000,-.Jumlah pendapatan kotor sebesar Rp.2.510.000,-/periode .Jumlah pendapatan bersih sebesar Rp.738.466,-/peternak, nilai B/C ratio sebesar 1,10. Analisis usaha ayam kampung di RTM atau peternak terlihat pada Tabel.4.

Tabel 4. Analisis ekonomi usaha ayam kampung di RTM .

\begin{tabular}{ccc}
\hline Uraian & Desa Mandalahayu & Desa Mandalawagi \\
\hline Biaya produksi & 1.743 .848$. & 1.771 .534 \\
\hline
\end{tabular}




\begin{tabular}{lcc}
\hline Pendapatan kotor/periode & 2.480 .000 & 2.510 .000 \\
Pendapatan bersih/perode & 736.150 & 738.466 \\
B/C & 1,08 & 1,10 \\
\hline
\end{tabular}

Sumber: Data diolah (2019)

Tabel 4, menunjukkan bahwa, perhitungan atas biaya tetap dilakukan dengan penyusutan atas umur kandang selama 1 tahun, peralatan dan obat-obatan dianggap habis pakai. Lahan yang digunakan milik peternak. Usaha ayam dengan pemeliaraan rata-rata antara 46-47 ekor/RTM//peternak tidak menguntungkan. RTM/peternak pada usaha pemeliharaan ayam biasanya, sebagai tabungan, pengisi waktu dan cara pemeliharananya cukup sederhana, sehingga dapat dinyatakan layak. Untuk mendapatkan keuntungan yang optimal, maka usaha ayam dapat dilakukan sebanyak 1000 ekor/peterak. Usaha tersebut untuk menghasilkan produksi telur konsusmi, telur tetas DOC, pullet, bibit dan ayam siap potong. Hampr semua RTM/peternak usaha pokoknya bertani, buruh tani, dagang dan usaha lainnya. Ayam dapat dijual sebagai sumber kebutuhan mendadak bagi peternak.

\section{KESIMPULAN DAN SARAN}

\section{Simpulan}

Hasil penelitian, secara umum pelaksanaan Program Bekerja di Desa Mandalahayu dan Desa Mandalawangi Kecamatan Salopa Kabupaten Tasikmalaya dapat dikatakan relatif baik ditinjau dari aspek kinerja pertumbuhan ayam dan tingkat kematian yang rendah. Pendapatan RTM/peternak di Desa Mandalahayu sebasar Rp.2.480.000,-/periode dengan B/C ratio sebesar 1,08 dan di Desa Mandalawangi sebasar Rp.2.510.000,-/periode dengan B/C ratio sebesar 1,10. Diharapkan Program bekerja Kementerian Pertanian, dapat pengentasan kemiskinan, dilakukan akserasi pembangunan pertanian di pedesaan, sehingga pendapatan peternak meningkat dan angka kemiskinan terus ditekan atau berkurang. Kondisi RTM di beberapa tempat sudah lebih baik, sejak tercatat sebagai RTM penerima ayam.

\section{Saran}

Disarankan dilakukan kembali sensus di RTM di Kecamatan Salopa, untuk informasi yang dapat dimanfaatkan Pemerintah secara akurat di masa yang akan datang.

\section{DAFTAR PUSTAKA}

Anantanyu, S., 2008. Tipe petani dan strategi pengembangan kelembagaan kelompok petani (Kasus di Provinsi Jawa Tengah). M'POWER, Otober 2008. Vol.8(8): 65-70.

Apriyantono, A. 2007. Lampiran Peraturan Menteri Pertanian Nomor: 273/Kpts/Ot.160/4/2007, tanggal 13 April 2007 tentang Pedoman Penumbuhan dan Pengembangan Kelompok Tani dan Gabungan Kelompok Tani. 1 
Adawiyah. C. Rabiatul. 2017. Urgensi komunikasi dalam kelompok kecil untuk mempercepat proses adopsi teknologi pertanian. PSEKP, Jurnal Forum Agro Ekonomi, 36(1)59-74.

Badan Litbang Pertanian. 2015. Surat Keputusan No 31/Kpts/OT.050/I/01/2015 tentang Pembentukan Tim Pengelola Laboratorium Inovasi Pertanian Badan Penelitian dan Pengembangan Peternakan. Badan Penelitian dan Pengembangan Pertanian.

Dewanti, R. dan G. Sihombing. 2012. Analisis pendapatan usaha peternakan ayam buras (Studi kasus di Kecamatan Tegalombo, Kabupaten Pacitan). Buletin Peternakan-UGM, Februari 2012, 36(1):48-56.

Zaenal Hasnelly, T. Sartika. S. Iskandar 2015. Kinerja Ayam Lokal Sentul Hasil Seleksi Sebagai Calon Galur Penjantan. Prosiding Seminar Unggas Lokal. Peran Unggas Lokal dalam Menunjang Industri Perunggasan di Indonesia. Fakultas Peternakan dan Pertanian Universitas Diponegoro. Semarang, 18 November 2015.

Iskandar S., Sartika T., Hasnelly Z., Gunawan B. 2016. Naskah ilmiah pelepasan galur ayam lokal pedaging SenSi Abu dan SenSi Putih. Badan Penelitian dan Pengembangan Pertanian. Balai Penelitian Ternak. Ciawi. Bogor

Iskandar, S. 2018. Ciptakan ayam lokal unggulan, [Internet] [Diunduh tgl, 18 Juni]. Terseda dari http://peternakan.litbang.pertanian.go.id/index.php/artikelmedia- cetak/48131-

Istikomah, Imam Suhadi dan Marhani. 2016. Analisis pendapatan dan elastilitas produksi usaha ternak ayam kampung pedaging intensif di Kecamatan Sangata Utara dan Bengalon, Kabupaten Kutai Timur. Jurnal Pertanan Terpadu, Mei 2016 6(1):98-109.

Loing, C. Jeane dan A. Makalew. 2016. Analisis finansial usaha ternak ayam kampung di kecamatan kawangkoan kawasan agropolitan Kabupaten Minahasa Jurnal LPPM Bidang Sains dan Teknologi Mei 2016, 3(1):51-56

Kementerian Pertanian 2015. Pengembangan Taman sains dan Teknologi Pertanian (TSTP). Badan Litbang Pertanian Jakarta, Pedum Umum, Desember 2015, hal.1-71

Kementerian Pertanian . 2018. Entaskan Kemiskinan, Kementan Genjot Program 'Bekerja' Kementerian Perrtanian. 2018. [Internet] [Diunduh tgl, 21 Mei 2019]. Tersedia dari https://finance.detik.com/artikel-ekonomi-bisnis/d4128357 /kentaska-genjot-program-bekerja,

Puslitbangnak. 2011. Spektrum diseminasi multi chanel kampung ternak domba terpadu. Puslitbang Peternakan [Internet]. [cited 21 Mei 2011]. http://peternakan.litbang.deptan.go.id/artikel/index/artikel/

Iskandar.S., T. Sarika, IGM. Harsna, Soeharsono. L. Yunia dan A. Eopiq. 2018. Panduan pemeliharaan ayam lokal unggul Badan Litbang pertanian. Program Bekerja, Kementerian Pertanian. Balai Penelitian Ternak Ciawi-Bogor 
Rosganda, E dan S. Rusdiana . 2012. Peluang usaha ternak ayam kampung dan manajemen usaha pada petani di pedesaan. Pros. Seminar Nasinal Unggal Lokal, Jakarta 4 Nopember 2012, hal. 104-109

Sulaeman Amran 2018. Entaskan Kemiskinan, Kementan Genjot Program 'Bekerja' [Internet] [Diunduh tgl, 23 Juni 2019]. Tersedia dari https: / finance.detik.com/artikel-ekonomi-bisnis/d-4128357/entaskankemiskinan-kementan-genjot-program-bekerja.

Sartika, T., dan S. Iskandar. 2007. Mengenal Plasma Nutfah Ayam Indonesia, dan pemanfaatnnya, Balai Penelitian Ternak Ciawi Bogor.

Schader, C., Muller, A. and El-Hage Scialabba, N. 2013. Sustainability and organic livestock modeling (SOL-m): Impacts of global upscalling of low-input and organic livestock production. Natural Resources Management and Environment Departement. FAO-Rome.

Wibowo, B., dan T. Sartika. 2010. Analisis kelayakan usaha pembibitan ayam kampung (lokal) pengghasil Day Old Chicken (DOC) di tingkat petani (Studi kasus kemlompok peternak ayam buras "Barokal" di Ciamis). Prosiding Seminar Nasional Teknologi Petenakan dan Veteriner, Bogor Juni 2010, hal 714-721

Zakaria, AK. 2010. Program pengembangan agribisnis kedelai dalam peningkatan produksi pendapatan petani. Jurnal Litbang Perrtanian.29(4):147-153. 